\title{
Peer-Delivered Cognitive Behavioral Training to Improve Functioning in Patients With Diabetes: A Cluster-Randomized Trial
}

Susan J. Andreae, PhD, MPH

Lynn J. Andreae, MPH

Josbua S. Ricbman, $P b D, M D^{3}$

Andrea L. Cherrington, MD, MPH

Monika M. Safford, MD

'Department of Kinesiology, University of

Wisconsin-Madison, Madison, Wisconsin

${ }^{2}$ Department of Medicine, University of Alabama at Birmingham, Birmingham, Alabama

${ }^{3}$ Department of Surgery, University of Alabama at Birmingham, Birmingham, Alabama

${ }^{4}$ Department of Medicine, Weill Cornell Medicine, New York, New York

AC Annals Journal Club selection; see inside back cover or http://www.ann fammed.org/site/AJC/.

Conflicts of interest: authors report none.

\section{CORRESPONDING AUTHOR}

Monika M. Safford, MD

Department of Medicine, Weill

Cornell Medicine, New York, NY

420 East $70^{\text {th }}$ Street, suite 340

New York, NY 10021

mms9024@med.cornell.edu

\begin{abstract}
PURPOSE Cognitive behavioral therapy (CBT)-based programs delivered by trained community members could improve functioning and pain in individuals who lack access to such programs. We tested the effectiveness of a peer-delivered diabetes self-management program integrating CBT principles in improving physical activity, functional status, pain, quality of life (QOL), and health outcomes in individuals with diabetes and chronic pain.
\end{abstract}

METHODS In this community-based, cluster-randomized controlled trial, intervention participants received a 3-month, peer-delivered, telephone-administered program. Attention control participants received a peer-delivered general health advice program. Outcomes were changes in functional status and pain (Western Ontario and McMaster Universities Osteoarthritis Index), QOL (Short Form 12), and physiologic measures (hemoglobin $A_{1 c}$, systolic blood pressure, body mass index); physical activity was the explanatory outcome.

RESULTS Of 195 participants with follow-up data, 80\% were women, 96\% African Americans, $74 \%$ had annual income $<\$ 20,000$, and $64 \%$ had high school education or less. At follow-up, compared with controls, intervention participants had greater improvement in functional status $(-10 \pm 13$ vs $-5 \pm 18$, $P=.002)$, pain $(-10.5 \pm 19$ vs $-4.8 \pm 21, P=.01)$, and QOL ( $4.8 \pm 8.8$ vs $3.8 \pm 8.8, P=.001)$. Physiologic measures did not change significantly in either group. At 3 months, a greater proportion of intervention than control participants reported no pain or did other forms of exercise when pain prevented them from walking for exercise.

CONCLUSION This peer-delivered CBT-based intervention improved functioning, pain, $\mathrm{QOL}$, and self-reported physical activity despite pain in individuals with diabetes and chronic pain. Trained community members can deliver effective CBTbased interventions in rural and under-resourced communities.

Ann Fam Med 2020;18:15-23. https://doi.org/10.1370/afm.2469.

\section{INTRODUCTION}

$\mathrm{R}$ ural communities in the Southeastern United States have the highest prevalence of diabetes in the nation. ${ }^{1}$ Area residents face considerable barriers to successful diabetes self-management, including lack of access to healthy foods, limited educational attainment, scarce health care resources, and poverty. ${ }^{2-4}$ In addition, up to $75 \%$ of adults with diabetes report chronic pain, and many also have depression, anxiety, and physical or emotional disabilities. ${ }^{5-9}$ Individuals with chronic pain are less likely to exercise, a critical component of diabetes selfmanagement. ${ }^{10,11}$ Although medications are widely used for chronic pain, they have limited appeal due to the opioid crisis and for diabetes specifically, due to the renal risks of nonsteroidal anti-inflammatory drugs and the liver toxicity of chronic acetaminophen use. ${ }^{12-16}$ Additional strategies to overcome pain as a barrier to physical activity for people living with diabetes are needed. 
Cognitive behavioral therapy (CBT) is an effective nonpharmacologic intervention for chronic pain, ${ }_{1}^{17}$ but CBT is not well studied in diabetes and chronic pain. ${ }^{18}$ CBT interventions improve functioning and quality of life in a variety of chronic pain settings, ${ }^{17,19-22}$ but many rural and underserved communities lack the health care infrastructure to provide CBT. For example, in some Alabama counties 1 in 3 adults aged $\geq 50$ years has diagnosed diabetes, up to $75 \%$ report chronic pain, and up to $38 \%$ live below the federal poverty level. ${ }^{6,23,24}$ Despite the high chronic disease burden, these counties have health care workforce shortages preventing the provision of services such as CBT. ${ }^{25,26} \mathrm{~A}$ potential solution to increase access to CBT programs is to train community members to deliver CBT-based programs as peer coaches.

Peer coaches, also called community health workers, lay health advisors, promotoras, or peer supporters, are trained community members who provide emotional and practical support for chronic disease management and prevention. ${ }^{27}$ Peer supporters provide emotional support, health education, and linkages to community resources. Because they are trusted members of the community with firsthand knowledge of the community's strengths and needs, peer coaches can provide tailored ongoing support. Moreover, there is increasing evidence that peer support can improve health behaviors in patients with conditions such as diabetes and chronic pain. ${ }^{27}$

While few peer support programs explicitly include CBT activities, most offer components designed to improve behavioral activation. For example, in addition to providing emotional support and diabetes education, many peer support programs include strategies such as tailored goal setting, problem solving, developing healthy coping strategies, and self-monitoring activities. ${ }^{28-32}$ Although there is evidence that trained community members can deliver components of CBT programs, few have included core elements such as cognitive restructuring. A notable exception is a CBTbased program that included cognitive restructuring delivered by trained community members; that intervention decreased postpartum depression by $50 \% .{ }^{33} \mathrm{Few}$ other studies have rigorously tested CBT-based programs delivered by peer coaches, however, and to our knowledge, none have examined a peer-coach-delivered CBT-based program specifically for diabetes and chronic pain. To address this gap, we conducted a clusterrandomized controlled trial in under-resourced regions in rural Alabama. We tested the hypothesis that a peercoach-delivered, CBT-based intervention called Living Healthy improves functional status, pain, health-related quality of life, metabolic parameters, and exercising despite pain in adults with chronic pain and diabetes. ${ }^{34}$

\section{METHODS}

\section{Theoretical Underpinnings of the Study}

This study was informed by social cognitive theory, 35,36 which proposes that self-efficacy operates with goals, outcome expectations, and perceived barriers and facilitators to influence behavior. The Living Healthy intervention emphasized empowerment through personalized goal setting using motivational interviewing. Social cognitive theory also proposes that peer modeling influences behavior, thus the intervention was delivered by peers who had completed the program themselves. The intervention also integrated principles of CBT, which focuses on minimizing catastrophizing through cognitive restructuring and modifying outcome expectations through self-monitoring and practice. The Living Healthy intervention emphasized the importance of replacing negative thinking with positive thinking using imagery and included self-monitoring homework.

\section{Study Design}

We used a cluster-randomized design to minimize contamination between the trial arms. Clusters were towns blocked on small ( $<1,000$ residents), medium $(1,000$ 1,999 residents), and large ( $\geq 2,000$ residents) sizes, with participants nested within towns. Towns were block randomized to the Living Healthy intervention or the General Health attention control program. Due to the nature of the trial, the participants, peer coaches, and study staff were not blinded to trial arm assignment, but data collection staff and analysts were blinded.

\section{Participants and Setting}

The trial was conducted in communities in rural Alabama, a region with a high burden of chronic diseases such as diabetes, hypertension, and obesity.,37 Community-dwelling adults who had been told by a doctor or nurse they had diabetes, wanted help with diabetes self-management, and reported experiencing chronic pain that affected usual activities for more than one-half of the previous month were eligible to participate. Individuals were excluded if they did not wish to work with a peer coach, did not have a primary care doctor, had an end-stage medical condition with limited life expectancy, planned to move out of the area within the next year, or were unable or unwilling to participate in a walking program.

\section{Participant Recruitment and Data Collection}

Participants were recruited using respondent-driven (or chain-referral) sampling, a technique developed to study populations that are historically difficult to recruit. ${ }^{38}$ Program staff presented the study at community events, health fairs, and churches. Flyers were posted at local medical offices, churches, libraries, 
stores, and other community meeting locations. In turn, the community members who were eligible and decided to participate in the study were asked to refer individuals in their social networks.

All interested individuals spoke to study staff on the telephone and were provided additional details regarding the study, had the opportunity to ask questions, and were screened for study eligibility. Data were collected at baseline and after 3 months and included a 45-minute telephone interview and an in-person visit. Participants received a portable DVD player for participating, which they used to watch the educational videos corresponding to their assigned study arm. All participants provided written informed consent. The study protocol was approved by the University of Alabama at Birmingham Institutional Review Board and was registered in clinicaltrials.gov (NCT02538055).

\section{Intervention Peer Coaches, Peer Training, and Program Description}

Ten coaches completed the 10-week Living Healthy program training and 9 were then matched with participants. All were African American women and had completed some college education or were college graduates. Coaches had previously partnered with the study team and therefore had nearly 2 years of experience in using motivational interviewing skills to help participants with diabetes self-management. ${ }^{32,39}$ All coaches either had diabetes or helped care for family members with diabetes.

The Living Healthy intervention development and peer-coach training is described elsewhere. ${ }^{34}$ Briefly, training consisted of 1 face-to-face session followed by 9 weeks of telephone sessions. Training emphasized roleplay and practicing program delivery. Coaches were certified for each program session to ensure they had mastered all program components. On average, coaches were matched with $13.6(\mathrm{SD} \pm 10.9$, range 2-28) participants who attended $6.6(\mathrm{SD} \pm 2.8$, range $0-8)$ intervention sessions.

The Living Healthy program integrated a CBT-based approach to overcome pain as a barrier to exercise with a diabetes self-management program. It consisted of 8 telephone sessions with a peer coach over a period of 3 months. Program content focused on 5 lifestyle management areas (healthy eating, physical activity, stress management, communication with health care provider, social support) and each session lasted between 30 and 60 minutes (Supplemental Appendix, available at http:// www.AnnFamMed.org/content/18/1/15/supp1/DC1/).

\section{Attention-Control Peer Coaches, Training, and Program Description}

Nine peer coaches were trained for the attentioncontrol General Health program. Training consisted of
4 sessions during which program content and activities were reviewed. Coaches were matched with an average of $12.0(\mathrm{SD} \pm 8.7$, range $2-25)$ participants who attended $7.6(\mathrm{SD} \pm 1.5$, range $0-8)$ General Health program sessions.

The attention-control group received an equal number of telephone sessions of similar duration with a coach covering topics that were independent of the study outcomes (dementia and Alzheimer's disease, breast cancer, colorectal cancer, osteoporosis and fall prevention, oral health, eye health, foot care, and driving safety). The sessions were developed to mimic the social support and attention being received by the intervention group.

\section{Peer Coach and Participant Interactions}

The Living Healthy (intervention) and General Health (attention control) programs were structured similarly. Participants received an activity book, a DVD player, and a program DVD. Living Healthy participants also received a health calendar that was used to track their homework and daily self-monitoring activities. Before the session with the coach, participants watched a 15 to 30 -minute video with that week's educational content. The telephone session with the coach reinforced the video's educational content through interactive activities. Intervention fidelity was monitored weekly during one-on-one meetings with coaches and review of program manuals.

\section{Outcomes and Measures}

The primary outcomes were changes between baseline and 3-month functional status and pain, measured using the Western Ontario and McMaster Universities Osteoarthritis Index (WOMAC), health-related quality of life (HQOL) measured using the Short Form 12 (SF12); and metabolic parameters (glycated hemoglobin $\left[\mathrm{A}_{1 \mathrm{c}}\right]$, systolic blood pressure $[\mathrm{SBP}]$, body mass index $[\mathrm{BMI}]) .{ }^{26,40,41}$ The explanatory outcome of self-reported physical activity was measured using questions assessing intensity and frequency of exercise, perception of physical activity compared with others, and physical activity when experiencing pain. Exercise intensity and frequency were assessed using the questions "How many times per week do you engage in intense physical activity, enough to work up a sweat?" and "Over the past 7 days, have you walked for exercise? If yes, how many days did you walk?"37 Physical activity when experiencing pain was assessed by asking the questions "Were there days you were unable to walk for exercise because of aches and pains?" If the participant responded "yes," they were asked, "On the days you were unable to walk because of pain, did you do other forms of exercise?" 


\section{Statistical Analysis}

The trial was designed for $80 \%$ power to detect clinically important differences in $\mathrm{A}_{1 \mathrm{c}}(0.4 \%)$ and SBP $(4$ $\mathrm{mm} \mathrm{Hg}$ ). The sample size calculations assumed $20 \%$ attrition and included a variance inflation factor to account for the cluster-randomized design. Differences in age, race, sex, education, annual household income, gender, and use of insulin between study arms were examined using frequency distributions of categorical variables and mean and standard deviations of continuous variables. Categorical baseline characteristics were compared using $\chi^{2}$ tests and continuous variables were compared using independent samples $t$-tests.

Differences in changes in outcomes from baseline to 3 months between intervention and control groups were tested using generalized estimating equations to account for clustering using an exchangeable correlation structure. Sensitivity analyses included imbalanced $(P<.1)$ baseline covariates in the models. All analyses were intention-to-treat, regardless of intervention dose received. Analyses were conducted using SAS software (SAS Institute, Inc).

\section{RESULTS}

Figure 1 shows the consolidated standards of reporting trials (CONSORT) diagram of study. Of the 757 community members screened for eligibility, 122 were allocated to the intervention (Living Healthy) and 108 were allocated to the attention-control condition (General Healtb). Thirty-five (15\%) of the 230 study participants $(26$ [21\%] from the Living Healthy program and 9 [8\%] from the General Health program) were lost to follow-up. There was no difference in sociodemographic characteristics or baseline measures of the study outcomes between those with and without follow-up.

\section{Baseline Characteristics}

Trial participants had a mean age of 59 years, 80\% women, 96\% African American, 74\% with annual income less than $\$ 20,000$, and $64 \%$ with a high school education or less (Table 1). The study sample had low physical functioning (Physical Component Summary [PCS] score 39), 87\% were obese, and $63 \%$ reported being unable to walk due to pain. Participants in the 2 trial arms were similar except that intervention-arm participants reported slightly more days per week exercising enough to work up a sweat (2.9) than attention-control participants $(2.2, P=.03)$.

\section{3-Month Outcomes}

Table 2 presents the change in outcome measures from baseline to 3 months in intervention participants compared with attention-control participants. Functional status improved in both groups, but there were significantly greater improvements in the intervention group in the WOMAC overall score as well as the functional limitation, stiffness, and pain subscales. Short Form 12 scores improved in both groups with no statistically significant group differences in PCS scores but a significant improvement in mental com-

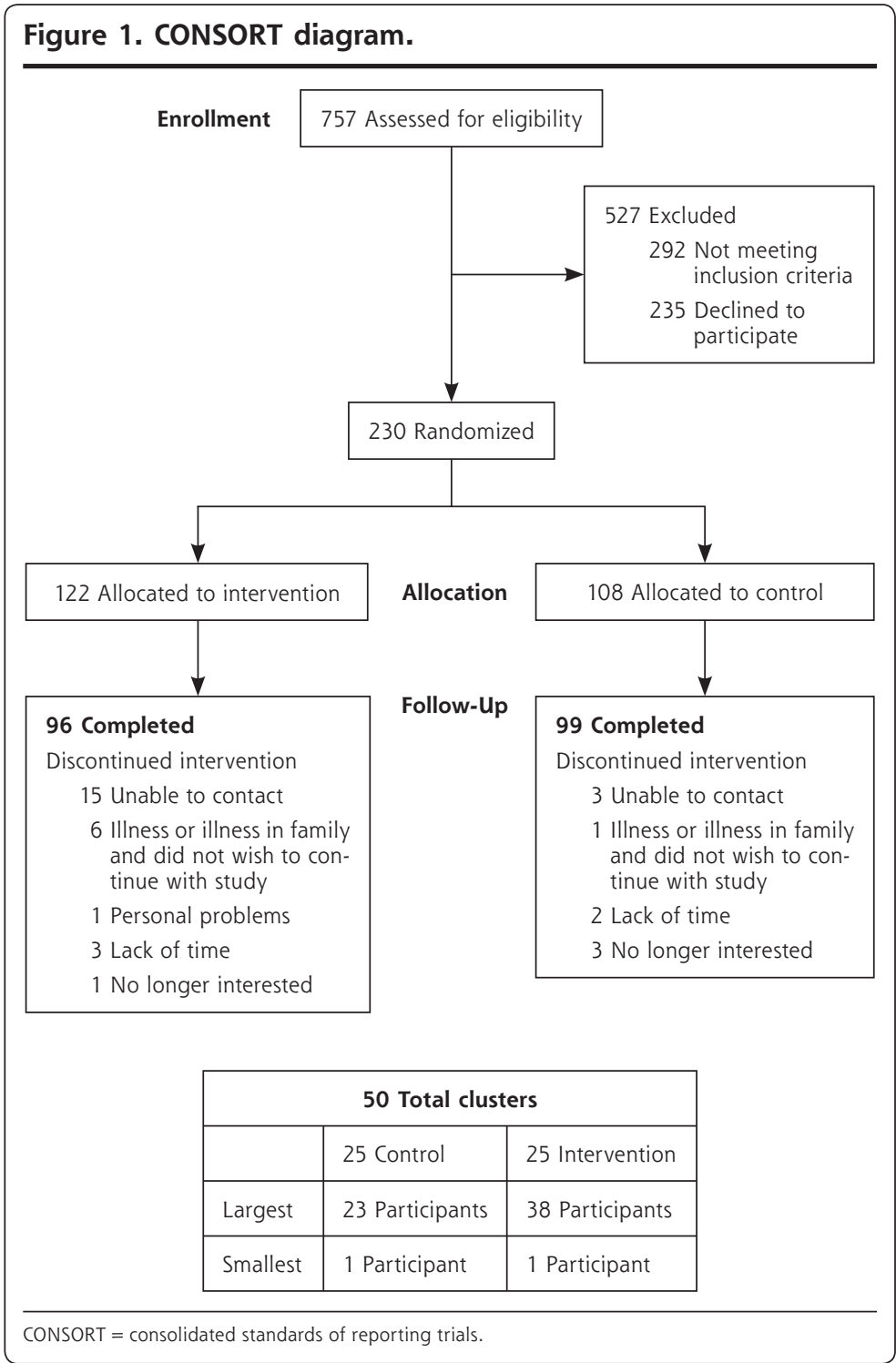


ponent summary (MCS) scores in the intervention group. There were no significant changes in $A_{1 c}, S B P$, or BMI in either trial arm.

Table 3 shows the changes in physical activity from baseline to 3 months in intervention participants compared with attention-control participants. There was a nonstatistically significant increase in mean days of physical activity intense enough to work up a sweat in both groups. Intervention participants had significant increases in mean days walked for exercise and reported an increase in perceived physical activity levels compared with others their age. Finally, a greater
Table 1. Baseline Characteristics of the 195 Participants Who Completed the Living Healthy Trial

\begin{tabular}{|c|c|c|c|c|}
\hline & $\begin{array}{c}\text { All } \\
N=195\end{array}$ & $\begin{array}{l}\text { Control } \\
n=99\end{array}$ & $\begin{array}{l}\text { Intervention } \\
\qquad \mathbf{n}=96\end{array}$ & $\begin{array}{c}P \\
\text { Value }^{a}\end{array}$ \\
\hline Mean age $\pm S D$ & $58.9 \pm 10.4$ & $57.9 \pm 10.8$ & $60.0 \pm 9.9$ & .15 \\
\hline Female, No. (\%) & $155(80)$ & $74(75)$ & $81(84)$ & .10 \\
\hline African American, No. (\%) & $188(96)$ & $94(95)$ & $94(98)$ & .27 \\
\hline \multicolumn{5}{|l|}{ Education, No. (\%) } \\
\hline$<$ High school & $55(28)$ & $32(32)$ & $23(24)$ & \multirow[t]{3}{*}{.38} \\
\hline $\begin{array}{l}\text { 12th grade, GED, high school } \\
\text { diploma }\end{array}$ & $70(36)$ & $32(32)$ & $38(40)$ & \\
\hline > High school education & $70(36)$ & $35(35)$ & $35(37)$ & \\
\hline \multicolumn{5}{|l|}{ Annual household income, No. (\%) } \\
\hline$<\$ 20,000$ & $132(74)$ & $62(68)$ & $70(80)$ & \multirow[t]{2}{*}{.08} \\
\hline$>=\$ 20,000$ & $47(26)$ & $29(32)$ & $18(20)$ & \\
\hline Mean WOMAC total score \pm SD ${ }^{b}$ & $41 \pm 20$ & $42 \pm 20$ & $40 \pm 20$ & .61 \\
\hline $\begin{array}{l}\text { Mean functional status subscale } \\
\text { score } \pm \text { SD }\end{array}$ & $40 \pm 22$ & $41 \pm 22$ & $39 \pm 22$ & .56 \\
\hline Mean stiffness subscale score \pm SD & $49 \pm 26$ & $49 \pm 25$ & $49 \pm 27$ & .92 \\
\hline Mean pain subscale score \pm SD & $42 \pm 22$ & $43 \pm 23$ & $42 \pm 21$ & .70 \\
\hline \multicolumn{5}{|l|}{ Health related quality of lifec } \\
\hline Mean MCS $\pm S D$ & $39 \pm 7$ & $39 \pm 7$ & $39 \pm 6$ & .39 \\
\hline Mean PCS $\pm S D$ & $39 \pm 9$ & $38 \pm 9$ & $39 \pm 9$ & .31 \\
\hline Mean hemoglobin $A_{1 c}, \% \pm S D$ & $8.3 \pm 2.1$ & $8.4 \pm 2.2$ & $8.2 \pm 2.1$ & .40 \\
\hline $\begin{array}{l}\text { Mean systolic blood pressure, } \\
\mathrm{mm} \mathrm{Hg} \pm \mathrm{SD}\end{array}$ & $133 \pm 21$ & $133 \pm 21$ & $133 \pm 20$ & .94 \\
\hline Mean body mass index, $\mathrm{kg} / \mathrm{m}^{2} \pm \mathrm{SD}$ & $37.5 \pm 8.0$ & $37 \pm 7.0$ & $38 \pm 9$ & .15 \\
\hline Body mass index $>30 \mathrm{~kg} / \mathrm{m}^{2}$, No. (\%) & $167(87)$ & $85(86)$ & $82(87)$ & .78 \\
\hline Taking Insulin, No. (\%) & $89(46)$ & $48(49)$ & $41(43)$ & .42 \\
\hline \multicolumn{5}{|l|}{ Explanatory variables } \\
\hline $\begin{array}{l}\text { Means days per week engaged in } \\
\text { intense } P A \pm S D^{d}\end{array}$ & $2.5 \pm 2.0$ & $2.2 \pm 1.9$ & $2.9 \pm 2.1$ & .03 \\
\hline $\begin{array}{l}\text { Mean days per week walked for } \\
\text { exercise } \pm \text { SD }\end{array}$ & $0.6 \pm 2.4$ & $0.6 \pm 2.3$ & $0.7 \pm 2.6$ & .88 \\
\hline \multicolumn{4}{|l|}{ PA despite pain, No. (\%)f } & \multirow[t]{4}{*}{.69} \\
\hline Did not have pain & $71(37)$ & $33(34)$ & $38(40)$ & \\
\hline Unable to walk, did other exercise & $53(27)$ & $28(29)$ & $25(26)$ & \\
\hline Unable to walk, no exercise & $70(36)$ & $37(38)$ & $33(34)$ & \\
\hline \multicolumn{3}{|l|}{$\begin{array}{l}\text { PA levels compared with others, } \\
\text { No. }(\%)^{g}\end{array}$} & & \multirow[t]{4}{*}{.42} \\
\hline Less active & $78(40)$ & $44(44)$ & $34(35)$ & \\
\hline Same as other my age & $58(30)$ & $28(28)$ & $30(31)$ & \\
\hline More active & $59(30)$ & $27(27)$ & $32(33)$ & \\
\hline \multicolumn{5}{|c|}{$\begin{array}{l}\text { GED = general equivalency diploma; MCS = mental health component score; PA = physical activity; PCS = physical } \\
\text { component score; WOMAC = Western Ontario and McMaster Universities Osteoarthritis Index. }\end{array}$} \\
\hline \multicolumn{5}{|c|}{ a $t$-test or $\chi^{2}$ testing between group differences. } \\
\hline \multicolumn{5}{|c|}{ bange 0-100; higher score indicates more pain, stiffness, and functional limitation. } \\
\hline \multicolumn{5}{|c|}{ 'Short Form 12; range 0-100; higher score indicates greater quality of life. } \\
\hline \multicolumn{5}{|c|}{ d "How many times per week do you engage in intense physical activity, enough to work up a sweat?" } \\
\hline \multicolumn{5}{|c|}{ e "Over the past 7 days, how many days did you walk for exercise?" } \\
\hline \multicolumn{5}{|c|}{ f"On days you were unable to walk for exercise due to pain, did you do other forms of exercise?" } \\
\hline g "How would you compare your activity leve & to others your a & & & \\
\hline
\end{tabular}

proportion of intervention participants reported at 3 months that they had no pain or did other forms of exercise when pain prevented them from walking for exercise (Figure 2). Fewer attention-control participants reported at 3 months that they exercised when they experienced pain or did other exercises when pain prevented them from walking (Figure 2).

Covariates that were potentially imbalanced $(P \geq .1)$ at baseline between the 2 groups included gender $(P=.1)$, income $(P=.08)$, and days walked for exercise $(P=.03)$. Sensitivity analyses adjusting for these variables yielded similar results as the unadjusted findings (Supplemental Table 1, available at http://www.AnnFamMed.org/ content/18/1/15/supp1/DC1/).

\section{DISCUSSION}

This CBT-based, peer-coachdelivered behavioral intervention in adults with diabetes and chronic joint pain living in rural Alabama resulted in self-reports of greater exercise despite pain and improvements in functioning, pain, and health-related quality of life compared with an attention control program over 3 months. The intervention did not result in any changes in physiologic parameters.

Although peer-support interventions are effective in improving health behaviors in individuals with chronic conditions, ${ }^{27}$ our study may be the first to test a peercoach-delivered program 
based on CBT principles for individuals with diabetes and chronic pain. All the peer coaches for this study were lifelong members of the study communities. They either had diabetes or cared for a family member with diabetes and understood the challenges of managing chronic conditions like diabetes in their communities. Although the peer coaches that delivered the intervention had no prior medical training and had no experience working with a research study before their experiences with this research team, they were able to deliver a program based on CBT principles.

Physical activity is a major component of diabetes self-care, resulting in improvements in glucose metabolism and assisting with efforts to maintain a healthy weight. Few interventions have targeted pain as a barrier to physical activity in diabetes. Intervention participants reported increased physical activity and had significant improvements in self-reported health-related quality of life, physical functioning, and pain compared with the attention control group. Compared with controls, the intervention group had greater increases in days walked for exercise as well as exercising despite pain. Although we did not have objective measures of physical activity, the increase in physical activity was likely because physical functioning and pain improved. Our findings are similar to previous studies examining the link between physical activity and functional status. ${ }^{42,43}$ Moreover, exercise interventions that incorporated psychosocial strategies were more effective in improving and maintaining mobility and physical functioning. ${ }^{44}$ Our trial extended these observations by demonstrating that CBT principles can overcome pain as a barrier to physical activity among sedentary and mostly obese individuals with diabetes and chronic pain, and that it is feasible to deliver a CBT-based intervention embedded in a diabetes self-management intervention using trained community members.

The improvement in mental functioning observed here is also consistent with past reports. Improved
MCS scores may have resulted in part from CBT and in part from linking physical activity to daily mood and pain levels, which was emphasized in the intervention. Previous studies have found that physical activity interventions were effective in improving chronic pain and psychological well-being, including mood. ${ }^{45-47}$ For example, DiLorenzo, et al found that an aerobic fitness program improved mood and other mental health outcomes which were maintained at 1 year. ${ }^{48}$ The Living Healthy intervention helped individuals link their activity levels to daily mood and pain levels, increased
Table 2. Mean Unadjusted Change in Primary Outcome Measures From Baseline to 3-Month Follow-Up in the Living Healthy Trial

\begin{tabular}{|c|c|c|c|c|}
\hline Outcome & Baseline & Follow-Up & $\begin{array}{l}\text { Raw Change } \\
\text { in Score } \pm S D\end{array}$ & $P$ Value $^{a}$ \\
\hline $\begin{array}{l}\text { WOMAC Total Score, } \\
\text { mean } \pm S D^{b}\end{array}$ & & & & .002 \\
\hline Con & $42 \pm 20$ & $37 \pm 19$ & $-5 \pm 18$ & \\
\hline Int & $40 \pm 20$ & $30 \pm 19$ & $-10 \pm 13$ & \\
\hline $\begin{array}{l}\text { Functional status subscale } \\
\text { score, mean } \pm \text { SD }\end{array}$ & & & & .01 \\
\hline Con & $41 \pm 22$ & $36 \pm 20$ & $-5 \pm 20$ & \\
\hline $\operatorname{lnt}$ & $39 \pm 22$ & $30 \pm 20$ & $-9 \pm 13$ & \\
\hline $\begin{array}{l}\text { Stiffness subscale score, } \\
\text { mean } \pm \text { SD }\end{array}$ & & & & .001 \\
\hline Con & $49 \pm 25$ & $43 \pm 28$ & $-6 \pm 25$ & \\
\hline Int & $49 \pm 27$ & $34 \pm 26$ & $-15 \pm 26$ & \\
\hline $\begin{array}{l}\text { Pain subscale score, } \\
\text { mean } \pm S D\end{array}$ & & & & .01 \\
\hline Con & $43 \pm 23$ & $37.9 \pm 19$ & $-4.8 \pm 21$ & \\
\hline Int & $42 \pm 21$ & $31 \pm 21$ & $-10.5 \pm 19$ & \\
\hline \multicolumn{5}{|l|}{ Quality of life, SF12 ${ }^{c}$} \\
\hline MCS scores, mean \pm SD & & & & .001 \\
\hline Con & $38.6 \pm 6.9$ & $42.5 \pm 7.0$ & $3.8 \pm 8.8$ & \\
\hline Int & $39.4 \pm 6.3$ & $44.2 \pm 6.8$ & $4.8 \pm 8.8$ & \\
\hline PCS scores, mean $\pm S D$ & & & & .11 \\
\hline Con & $38.1 \pm 8.7$ & $39.5 \pm 8.4$ & $1.4 \pm 8.8$ & \\
\hline Int & $39.4 \pm 8.9$ & $40.4 \pm 8.9$ & $1.0 \pm 9.6$ & \\
\hline $\begin{array}{l}\text { Hemoglobin } A_{1 c} \text { level, \%, } \\
\text { mean } \pm S D\end{array}$ & & & & .85 \\
\hline Con & $8.4 \pm 2.2$ & $8.4 \pm 1.9$ & $0.00 \pm 1.3$ & \\
\hline Int & $8.2 \pm 2.1$ & $8.3 \pm 2.0$ & $0.13 \pm 1.2$ & \\
\hline $\begin{array}{l}\text { Systolic blood pressure, } \\
m m H g, \text { mean } \pm S D\end{array}$ & & & & .26 \\
\hline Con & $133 \pm 21$ & $129 \pm 20$ & $-4.5 \pm 17.6$ & \\
\hline Int & $133 \pm 20$ & $132 \pm 22$ & $-1.0 \pm 20.0$ & \\
\hline $\begin{array}{l}\text { Body mass index, } \mathrm{kg} / \mathrm{m}^{2} \\
\text { mean } \pm S D\end{array}$ & & & & .99 \\
\hline Con & $36.7 \pm 7.1$ & $36.8 \pm 7.1$ & $0.03 \pm 1.3$ & \\
\hline Int & $38.3 \pm 8.8$ & $38.2 \pm 8.7$ & $-0.07 \pm 1.5$ & \\
\hline
\end{tabular}

Con = control group; GEE = general estimating equation; Int = intervention group; MCS = Mental Health Component Score; PCS = Physical Component Score; SF-12 = Standard Form 12; WOMAC = Western Ontario and McMaster Universities Osteoarthritis Index.

a GEE models testing the difference in the change from baseline to follow-up between groups, adjusting for clustering and baseline values.

${ }^{b}$ Range 0-100; higher score indicates more pain, stiffness, and functional limitation.

' Range 0-100; higher score indicates greater quality of life. 
Table 3. Mean Change in Physical Activity Measures From Baseline to 3-Month Follow-Up in the Living Healthy Trial

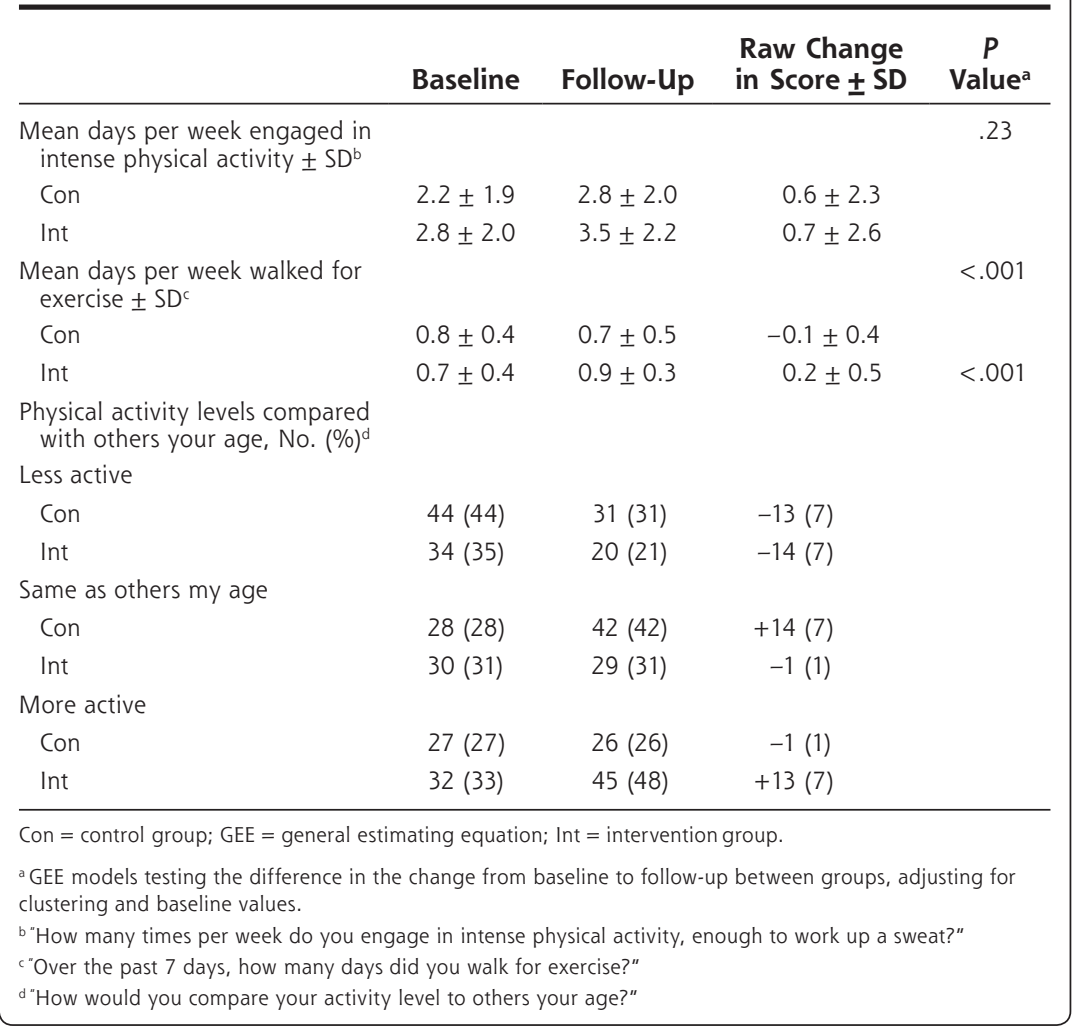

self-reported physical activity, and thereby improved functional status, pain, and quality of life. Although longer follow-up for the durability of these benefits is needed, our findings are significant for communities that are heavily burdened by chronic diseases like diabetes but lack the infrastructure to provide CBT programs delivered by health professionals.

These findings have implications for physical activity as an approach to the management of chronic pain beyond diabetes. Nonpharmacologic strategies to manage chronic pain and increase physical activity are urgently needed as the opioid crisis continues in the United States. Whether a promising intervention such as the one studied here can be used to reduce the use of opioids to treat chronic pain is worthy of further study.

This study's strengths include the testing of a theory-driven

Figure 2. Change from baseline to follow-up in the number of participants who did not have pain that prevented them from walking, had pain but did other forms of exercise, and had pain but did not do other exercise.

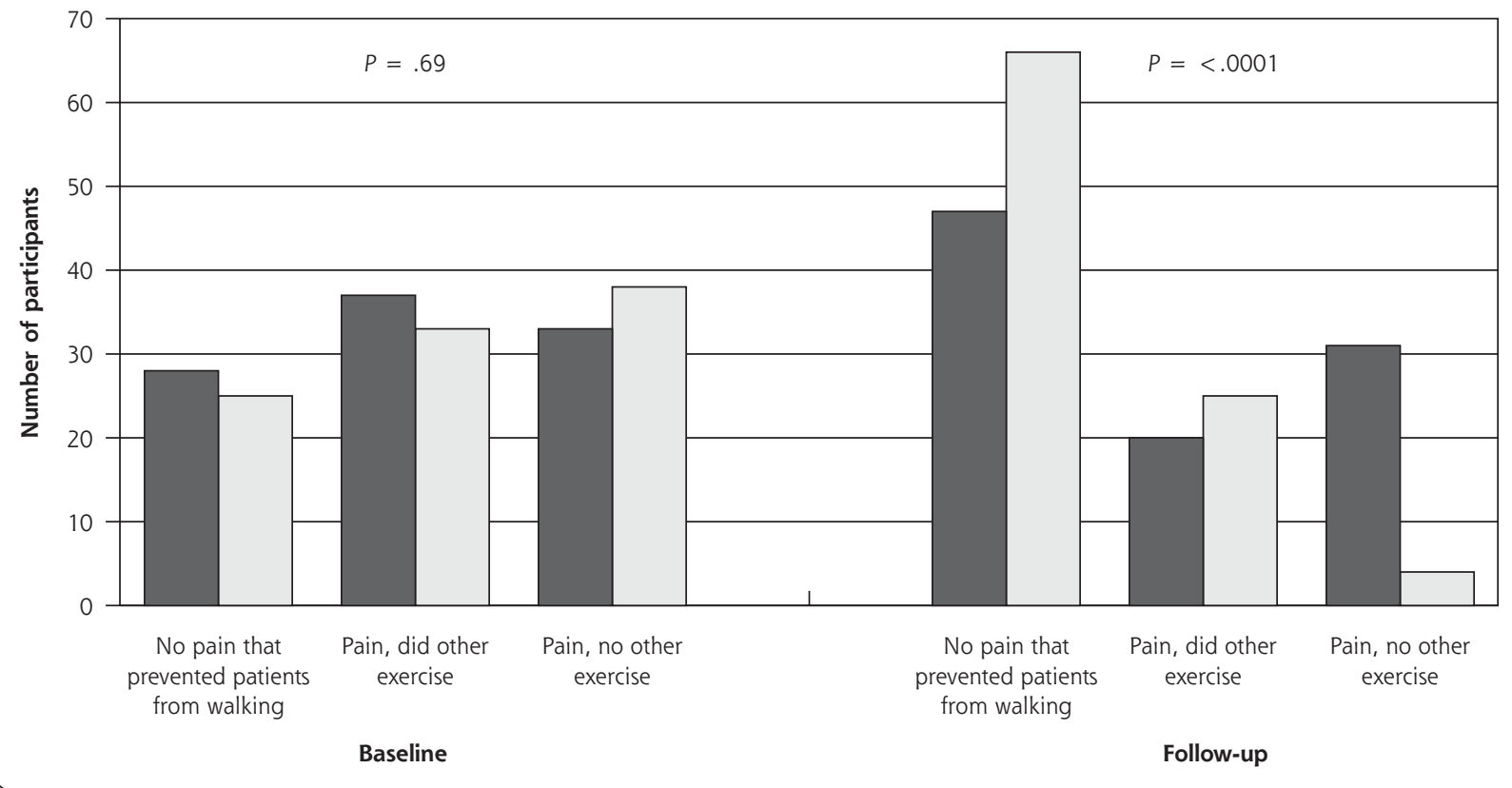


intervention and the robust cluster-RCT design that incorporated an attention control, assuring that the results can be attributed to CBT. Limitations include the lack of objective physical activity and functional status measures. Because physical activity frequency and intensity were obtained through participant selfreport, they may have overestimated or underestimated true activity levels. Furthermore, the relatively short duration of the trial did not allow much time for physiologic measures to change or to assess participants' long-term adherence. While the study setting and population was a strength, it also may have limited the generalizability of the findings. Participants in this sample were mostly women, possibly limiting generalizability to men. In addition, chain referral sampling method was used as the primary recruitment strategy, a method that is specifically designed to reach community members among whom trust is required to initiate contact, as was the case for our targeted population. We have no reason to believe that the intervention would be less impactful in more average populations, but as it is a non-probability method of recruitment, it may impact the generalizability of findings for more average populations.

Finally, our peer coaches had prior training and experience providing peer support in a diabetes selfmanagement intervention. The peer coaches in the intervention group received approximately 30 hours of training over 10 weeks for this study. Because of their prior experience with providing peer support, we were able to focus the training on the CBT components and activities of the program. Therefore, additional training on basic skills required in peer support programs, such as motivational interviewing skills and goal setting, will be needed when implementing this intervention with community members with no prior experience as peer coaches. The additional time and resources that will be needed for training for a new setting, however, is not an insurmountable barrier to implementation. There is considerable variability in training for peer support interventions in the literature. A recent review found that the mean length and duration of training was 41.3 hours with a range from 4 to 240 hours. ${ }^{49}$ Despite these differences, key characteristics of peer support programs are that they provide ongoing emotional and social support, help in daily management of a health condition, and link participants to resources by individuals who understand the challenges of daily management within that community's context. ${ }^{50}$ The primary role for the peer coaches of this study reflected these key characteristics. Their role was to provide ongoing and regular support and help guide participants through a structured program via a program activity book.
In conclusion, a theory-driven, CBT-based diabetes self-management empowerment intervention that focused on overcoming pain as a barrier to physical activity delivered by trained peer coaches improved selfreported physical activity, functioning, pain, and quality of life in individuals with diabetes and chronic pain. This study demonstrates the potential of using community members to deliver structured CBT-based interventions to improve health outcomes in resource-poor regions.

To read or post commentaries in response to this article, see it online at http://www.AnnFamMed.org/content/18/1/15.

Key words: chronic pain; diabetes; community peer coaches; community health workers; cognitive behavioral therapy

Submitted July 13, 2018; submitted, revised, April 19, 2019; accepted May 16, 2019.

Funding support: This study was supported by grant R18HS019239 (PI: Safford) from the Agency for Healthcare Quality and Research.

Trial registration: clinicaltrials.gov (NCT02538055)

Supplemental materials: Available at http://www.AnnFamMed. org/content/18/1/15/suppl/DC1/.

\section{References}

1. Barker LE, Kirtland KA, Gregg EW, Geiss LS, Thompson TJ. Geographic distribution of diagnosed diabetes in the U.S.: a diabetes belt. Am J Prev Med. 2011;40(4):434-439.

2. Hale NL, Bennett KJ, Probst JC. Diabetes care and outcomes: disparities across rural America. J Community Health. 2010;35(4):365-374.

3. Druss BG, Marcus SC, Olfson M, Tanielian T, Elinson L, Pincus HA. Comparing the national economic burden of five chronic conditions. Health Aff (Millwood). 2001;20(6):233-241.

4. Vogeli $C$, Shields $A E$, Lee $T A$, et al. Multiple chronic conditions: prevalence, health consequences, and implications for quality, care management, and costs. J Gen Intern Med. 2007;22(Suppl 3): 391-395.

5. Sudore RL, Karter AJ, Huang ES, et al. Symptom burden of adults with type 2 diabetes across the disease course: diabetes $\varepsilon$ aging study. J Gen Intern Med. 2012;27(12):1674-1681.

6. Herbert MS, Varley AL, Andreae SJ, Goodin BR, Bradley LA, Safford MM. Association of pain with $\mathrm{HbA1c}$ in a predominantly black population of community-dwelling adults with diabetes: a crosssectional analysis. Diabet Med. 2013;30(12):1466-1471.

7. Li C, Ford ES, Zhao G, Ahluwalia IB, Pearson WS, Mokdad AH. Prevalence and correlates of undiagnosed depression among U.S. adults with diabetes: the Behavioral Risk Factor Surveillance System, 2006. Diabetes Res Clin Pract. 2009;83(2):268-279.

8. Anderson RJ, Freedland KE, Clouse RE, Lustman PJ. The prevalence of comorbid depression in adults with diabetes: a meta-analysis. Diabetes Care. 2001;24(6):1069-1078.

9. Li C, Barker L, Ford ES, Zhang X, Strine TW, Mokdad AH. Diabetes and anxiety in US adults: findings from the 2006 Behavioral Risk Factor Surveillance System. Diabet Med. 2008;25(7):878-881.

10. Krein SL, Heisler M, Piette JD, Butchart A, Kerr EA. Overcoming the influence of chronic pain on older patients' difficulty with recommended self-management activities. Gerontologist. 2007;47(1):61-68.

11. Krein SL, Heisler M, Piette JD, Makki F, Kerr EA. The effect of chronic pain on diabetes patients' self-management. Diabetes Care. 2005;28(1):65-70. 
12. Wehling M. Non-steroidal anti-inflammatory drug use in chronic pain conditions with special emphasis on the elderly and patients with relevant comorbidities: management and mitigation of risks and adverse effects. Eur J Clin Pharmacol. 2014;70(10):1159-1172.

13. Huerta C, Castellsague J, Varas-Lorenzo C, García Rodríguez LA. Nonsteroidal anti-inflammatory drugs and risk of ARF in the general population. Am J Kidney Dis. 2005;45(3):531-539.

14. Harirforoosh S, Jamali F. Renal adverse effects of nonsteroidal antiinflammatory drugs. Expert Opin Drug Saf. 2009;8(6):669-681.

15. Gautam S, Franzini L, Mikhail OI, Chan W, Turner BJ. Longitudinal analysis of opioid analgesic dose and diabetes quality of care measures. Pain Med. 2015;16(11):2134-2141.

16. Rahimi Darabad B, Vatandust J, Pourmousavi Khoshknab MM, Hajahmadi Poorrafsanjani M. Survey of the effect of opioid abuse on the extent of coronary artery diseases. Globaljournal of Health Science. 2014;6(7 Spec No):83-91.

17. Turner JA, Holtzman S, Mancl L. Mediators, moderators, and predictors of therapeutic change in cognitive-behavioral therapy for chronic pain. Pain. 2007;127(3):276-286.

18. Hofmann SG, Asnaani A, Vonk IJ, Sawyer AT, Fang A. The efficacy of cognitive behavioral therapy: a review of meta-analyses. Cognit Ther Res. 2012;36(5):427-440.

19. McQuay HJ, Moore RA, Eccleston C, Morley S, Williams AC. Systematic review of outpatient services for chronic pain control. Health Technol Assess. 1997;1(6):i-iv, 1-135.

20. Turner JA, Clancy S. Comparison of operant behavioral and cognitive-behavioral group treatment for chronic low back pain. J Consult Clin Psychol. 1988;56(2):261-266.

21. Moore JE, Von Korff M, Cherkin D, Saunders K, Lorig K. A randomized trial of a cognitive-behavioral program for enhancing back pain self care in a primary care setting. Pain. 2000;88(2):145-153.

22. Bradley LA, Young LD, Anderson KO, et al. Effects of psychological therapy on pain behavior of rheumatoid arthritis patients. Treatment outcome and six-month followup. Arthritis Rheum. 1987; 30(10):1105-1114.

23. ADPH. Diabetes in Alabama: A Report from the Alabama Department of Public Health. Montgomery, Alabama: Alabama Department of Public Health;2010.

24. United States Census Bureau / American FactFinder. 2010 Demographic Profile Data. U.S. Census Bureau. http://factfinder2.census. gov. Published 2010. Accessed Aug 2014.

25. Aron L, Honberg R, Duckworth K, et al. Grading the States 2009: A Report on America's Health Care Systems for Adults with Serious Mental Illness. Arlington, VA: National Alliance on Mental Illness; 2009.

26. Bellamy N, Buchanan WW, Goldsmith CH, Campbell J, Stitt LW. Validation study of WOMAC: a health status instrument for measuring clinically important patient relevant outcomes to antirheumatic drug therapy in patients with osteoarthritis of the hip or knee. J Rheumatol. 1988;15(12):1833-1840.

27. Fisher EB, Boothroyd RI, Elstad EA, et al. Peer support of complex health behaviors in prevention and disease management with special reference to diabetes: systematic reviews. Clin Diabetes Endocrinol. 2017;3:4

28. Lujan J, Ostwald SK, Ortiz M. Promotora diabetes intervention for Mexican Americans. Diabetes Educ. 2007;33(4):660-670.

29. Babamoto KS, Sey KA, Camilleri AJ, Karlan VJ, Catalasan J, Morisky DE. Improving diabetes care and health measures among hispanics using community health workers: results from a randomized controlled trial. Health Educ Behav. 2009;36(1):113-126.

30. Brown SA, Garcia AA, Kouzekanani K, Hanis CL. Culturally competent diabetes self-management education for Mexican Americans: the Starr County border health initiative. Diabetes Care. 2002;25(2): 259-268.
31. DePue JD, Dunsiger $S$, Seiden AD, et al. Nurse-community health worker team improves diabetes care in American Samoa: results of a randomized controlled trial. Diabetes Care. 2013;36(7):1947-1953.

32. Safford MM, Andreae S, Cherrington AL, et al. Peer Coaches to improve diabetes outcomes in rural Alabama: a cluster randomized trial. Ann Fam Med. 2015;13(Suppl 1):S18-S26.

33. Rahman A, Malik A, Sikander S, Roberts C, Creed F. Cognitive behaviour therapy-based intervention by community health workers for mothers with depression and their infants in rural Pakistan: a clusterrandomised controlled trial. Lancet. 2008;372(9642):902-909.

34. Andreae SJ, Andreae LJ, Cherrington AL, et al. Development of a community health worker-delivered cognitive behavioral training intervention for individuals with diabetes and chronic pain. Fam Community Health. 2018;41(3):178-184.

35. Butler AC, Chapman JE, Forman EM, Beck AT. The empirical status of cognitive-behavioral therapy: a review of meta-analyses. Clin Psychol Rev. 2006;26(1):17-31.

36. Bandura A. Health promotion by social cognitive means. Health Educ Behav. 2004;31(2):143-164.

37. The Framingham Heart Study. National Heart, Lung, and Blood Institute and Boston University. Framingham, MA.

38. Heckathorn D. Respondent-driven sampling: a new approach to the study of hidden populations. Soc Probl. 1997;44(2):174-199.

39. Cherrington A, Martin MY, Hayes $M$, et al. Intervention mapping as a guide for the development of a diabetes peer support intervention in rural Alabama. Prev Chronic Dis. 2012;9:E36.

40. Chang A, Frank J, Knaebel J, Fullam J, Pardo S, Simmons DA. Evaluation of an over-the-counter glycated hemoglobin (A1C) test kit. J Diabetes Sci Technol. 2010;4(6):1495-1503.

41. Ware J Jr, Kosinski M, Keller SDA. A 12-Item short-form health survey: construction of scales and preliminary tests of reliability and validity. Med Care. 1996;34(3):220-233.

42. Brach JS, FitzGerald S, Newman AB, et al. Physical activity and functional status in community-dwelling older women: a 14-year prospective study. Arch Intern Med. 2003;163(21):2565-2571.

43. Bauman A, Merom D, Bull FC, Buchner DM, Fiatarone Singh MA. Updating the evidence for physical activity: summative reviews of the epidemiological evidence, prevalence, and interventions to promote "active aging". Gerontologist. 2016;56(Suppl 2):S268-S280.

44. Ross LA, Schmidt EL, Ball K. Interventions to maintain mobility: what works? Accid Anal Prev. 2013;61:167-196.

45. Penny KI, Purves AM, Smith BH, Chambers WA, Smith WC. Relationship between the chronic pain grade and measures of physical, social and psychological well-being. Pain. 1999;79(2-3):275-279.

46. Tse MM, Wan VT, Ho SS. Physical exercise: does it help in relieving pain and increasing mobility among older adults with chronic pain? J Clin Nurs. 2011;20(5-6):635-644.

47. Naugle KM, Naugle KE, Riley JL III. Reduced modulation of pain in older adults after isometric and aerobic exercise. J Pain. 2016;17(6): 719-728.

48. DiLorenzo TM, Bargman EP, Stucky-Ropp R, Brassington GS, Frensch PA, LaFontaine T. Long-term effects of aerobic exercise on psychological outcomes. Prev Med. 1999;28(1):75-85.

49. Kim K, Choi JS, Choi E, et al. Effects of community-based health worker interventions to improve chronic disease management and care among vulnerable populations: a systematic review. Am J Public Health. 2016;106(4):e3-e28.

50. Fisher EB, Ballesteros J, Bhushan N, et al. Key features of peer support in chronic disease prevention and management. Health Aff (Millwood). 2015;34(9):1523-1530. 